\title{
Spectrum of Ocular Trauma Among Children in Tertiary Eye Hospital of Nepal
}

\author{
Kafle $P A,{ }^{1 *}$ Shrestha $J B^{2}$
}

\begin{abstract}
Affiliation:
1. Head, Department of Occuloplasty, Biratnagar Eye Hospital, Biratnagar, Morang

2. Associate Professor, B. P. Koirala Lions Center for Opthalmic Studies, Kathmandu
\end{abstract}

\section{ARTICLE INFO}

Article History

$\begin{array}{ll}\text { Received } & \text { 27Aug, } 2016 \\ \text { Accepted }: & 27 \text { Sept, } 2016 \\ \text { Published : } 20 \mathrm{Dec}, 2016\end{array}$

(C) Authors retain copyright and grant the journal right of first publication with the work simultaneously licensed under Creative Commons Attribution License CC - BY 4.0 that allows others to share the work with an acknowledgement of the work's authorship and initial publication in this journal.

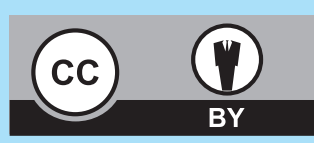

* Corresponding Author

Dr. Prerna Arjyal Kafle

Head, Department of Occuloplasty

Biratnagar Eye Hospital, Biratnagar, Rani, Nepal

Email: arjyalprerna@gmail.com

\section{Citation}

Kafle PA, Shrestha JB. Spectrum of Ocular Trauma Among Children in Tertiary Eye Hospital of Nepal. BJHS 2016; 1 (1) 1 : 33-37.

\section{ABSTRACT}

\section{Introduction}

Ocular trauma is an important cause of monocular blindness thus by recognizing its distribution and causes of ocular injury could potentially help to prevent ocular injury thereby reducing ocular injury related blindness.

\section{Objective}

To determine the epidemiology and causes of childhood ocular trauma in tertiary eye hospital of Nepal.

\section{Methodology}

This is hospital based cross sectional prospective study conducted among150 cases of pediatric age group (<15years) patients affected by ocular trauma during January 2010 to June 2011 at BP Koirala Lions Center for Ophthalmic Studies in Kathmandu, Nepal. Age, sex, mechanism andplace of trauma, presenting visual acuity and ocular findings in injured eye were analyzed.

\section{Results}

Majority of ocular trauma occurred in children aged group $\leqslant 5$ years (39.3\%). Among 150 study cases, boys 105(70\%) predominate over girls 45 (30\%). Early presentation within 24 hours was found in 82 (54.7\%) cases. Closed globe injuries accounted for $75 \%$ ocular injuries and sharp objects (51\%) was most frequent object responsible for ocular trauma. $57 \%$ of child had normal vision at presentation with subconjunctival hemorrhage $(26 \%)$ being most common ocular finding and among all $41.33 \%$ of children needed hospitalization for observation and further treatment.

\section{Conclusion}

Children are vulnerable to eye injuries and most of them are preventable. House being the most common place for ocular trauma in this study hence good parental supervision can significantly prevent ocular trauma related visual disability and blindness. Implementationof well-established safety precautions environment at school can potentially reduce ocular trauma among children.

\section{KEYWORDS}

Childhood ocular trauma, closed globe injuries, open globe injuries 


\section{INTRODUCTION}

Ocular trauma is a leading cause of visual impairment and blindness in young adults and children resulting in ophthalmic morbidity and monocular blindness all over of the world. ${ }^{1}$ The functional and cosmetic defect has a significant impact on the personality and lifestyle of the affected individuals. The peculiar anatomic features and the risk of amblyopia cause functional loss inspite of a good anatomic reconstruction. ${ }^{2}$ The significance of the problem is compounded by the findings of various studies that a majority of these injuries are preventable, ${ }^{3-6}$ thus making it an issue of great social and medical concern. The Nepal national blindness survey conducted in the year 1981 has revealed $2.4 \%$ of the populations were monocular blind due to eye injury. Tribhuwan University Teaching Hospital (TUTH) study showed $21.1 \%$ and the Bhaktapur eye survey showed $0.7 \%$ of blindness due to trauma. ${ }^{7-8}$ Eye trauma in childhood and its adnexa represent approximately $4-20 \%$ of all eye injuries. ${ }^{2}$ By identifying any underlying factors in the etiology of serious injuries, it may be possible to design effective methods for reducing the incidence of visually damaging trauma. ${ }^{6}$

The present study was carried out to determine the nature and causes of injury, duration between injury and presentation and impact of ocular trauma in children.

\section{METHODOLOGY}

This is prospective cross sectional hospital based study (January 2010 - June 2011) conducted at BP Koirala Lions Center for Ophthalmic Studies among the children having history of ocular injuries attending either BPKLCOS or Emergency department of TUTH,we included 150 cases of 145 children during the study period.Consent was obtained from parents of all children and institutional review committee approval was received prior to this study. Those who did not agree to get either medical or surgical treatment in our hospital and whose presenting visual acuity could not be taken were excluded from the study. Specially designed Performa was used which included information on demographic data, nature and cause of injury and duration between injury and presentation for admission. Ocular injuries were classified into open globe injuries, closed globe injuries and lid injuries as given by international trauma classification group.

Visual acuity assessment was performed with catford drum and k-pictures and Lea-symbols in preverbal children. Snellen's distant visual acuity chart was used for the verbal and school going children. The cases where surgical intervention or hospitalization was not required were treated medically on OPD basis. Data entry and analysis was done with SPSS 16.0 version.

\section{RESULTS}

Out of 150 ocular injuries, male child had higher incidence of ocular injury in 105 eyes compared to 45 eyes in female children and male to female ratio was 2.3:1. Mean age of study children was 7.2 years with mean age of male children was $7.63 \pm 3.8$ years whereas that of female children was $6.2 \pm 4.0$ years which was found to be statistically significant ( $P$ value 0.041$)$. Ocular trauma occurred frequently in age group of $0-5$ years $(39.3 \%)$ followed by $6-10$ years $(36 \%)$ and $>10$ years age group (24.7\%). Among 150 cases of ocular injury 140 (97\%) was unilateral and $5(3 \%)$ children sustain bilateral eye injury. Right eye injury was observed in 78(52\%) of cases and $72(48 \%)$ in left eye. $54.7 \%$ of ocular injury cases presented within 24 hours of eye injury as illustrated in table 1.

\section{Table 1: Demographic Pattern of Children With Ocular Trauma}

Characteristics

No. of Participants

Percentage (\%)

\begin{tabular}{|c|c|c|c|}
\hline Age & (mean $=7.2$ years) & & \\
\hline & $>0-5$ years & 59 & 39.3 \\
\hline & $>5-10$ years & 54 & 36 \\
\hline & $>10-15$ years & 37 & 24.7 \\
\hline Sex & & & \\
\hline & Male & 105 & 70 \\
\hline & Female & 45 & 30 \\
\hline Eye Ir & Ivement & & \\
\hline & Right Eye & 78 & 52 \\
\hline & Left Eye & 72 & 48 \\
\hline & Unilateral Cases & 140 & 97 \\
\hline & Bilateral Cases & 5 & 3 \\
\hline Ocule & jury to time of Presentatio & & \\
\hline & $>24$ hours & 82 & 54.7 \\
\hline & $>24$ hours upto 1 week & 58 & 38.7 \\
\hline & $>1$ week upto $<1$ month & 5 & 3.3 \\
\hline & $>1$ month & 5 & 3.3 \\
\hline
\end{tabular}

House was common site for ocular casualty followed by playground and school classroom accounting for $43 \%, 38 \%$ and $17 \%$ respectively. Sharp object (51\%) was most common object responsible for ocular injury among study children as shown in table 2. 
Table 2: Place and agent causing ocular trauma

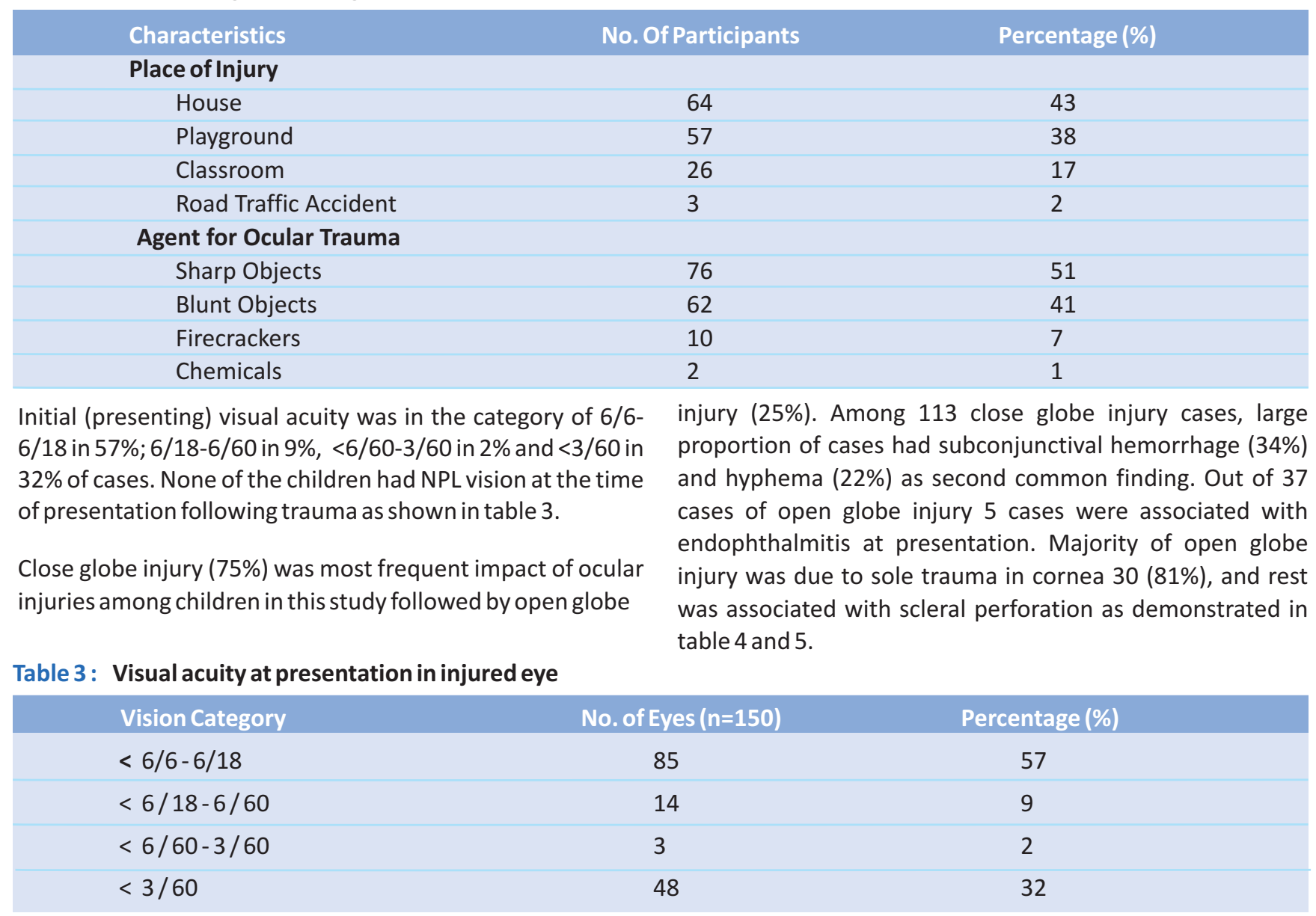

Table 4. Classification of ocular trauma among injured eye of children

\begin{tabular}{|ccc|}
\hline Type of Eye Injury & No. of Eyes $(\mathbf{n = 1 5 0 )}$ & Percentage $(\%)$ \\
\hline Open Globe Injury & $\mathbf{3 7}$ & $\mathbf{2 5}$ \\
\hline Zone I & 30 & 2 \\
\hline Zone II & 4 & $\mathbf{7 5}$ \\
\hline Zone I+ II & 1 & \\
\hline Zone I+ II + III & 113 & \\
\hline Close Globe Injury & 69 & \\
Zone I & 25 & \\
Zone II & 3 & \\
Zone III & &
\end{tabular}

Table 5: Impact of ocular injury among trauma eyes

$\begin{array}{lcc}\text { Ocular Impact of Trauma } & \text { No. of Eyes }(\mathbf{n = 1 5 0 )} & \text { Percentage }(\%) \\ \text { Subconjuncitval Hemorrhage } & 39 & 26 \\ \text { Hyphema } & 25 & 17 \\ \text { Conjunctivities } & 6 & 4 \\ \text { Lid Ecchmosis } & 8 & 5 \\ \text { Lid Laceration } & 8 & 5 \\ \text { Corneal Ulcer } & 9 & 6 \\ \text { Corneal Foreign Body } & 9 & 6 \\ \text { Corneo-scleral Perforation } & 37 & 25 \\ \text { Commotio Retinae, Retinal } & & 2 \\ \text { Ischemia } & 3 & 2 \\ \text { Conjunctival Laceration } & 3 & 2 \\ \text { Corneal Abrasion } & 3 & \end{array}$




\section{DISCUSSION}

We found male children had higher tendency for ocular injury than female which is similar to findings of other literatures such as Caroline J MacEwen et $a{ }^{1},{ }^{10}$ Shoja et al ${ }^{14}$ Saxena et. al ${ }^{18}$ and this may be due to fact that girl children are more involved with indoor games where as boys are involved in more outdoor and aggressive games. However, in contrast to the higher frequency of ocular trauma in younger age group 0-5 years in this study, other study have shown 5-10 years of age group children more vulnerable for ocular trauma. ${ }^{9}$ This variation of finding may be possibly due to lack of facility for younger children surgery and this may be the reason for relative older children as common age for ocular trauma in other study in compare to our current study.

House was the commonest place for eye injury (43\%) as in many similar studies by Kaur et al, ${ }^{11}$ Angelino et.al. ${ }^{13}$ This is followed by $38 \%$ in playground and school classroom (17\%) as third site for ocular injury. This disagrees with study findings from MacEwen et al where school is more frequent than playground. ${ }^{10}$ Study done in western Nepal showed $55.5 \%$ of the children had sustained trauma in the field. ${ }^{9}$

In this study the most frequent agent of eye injury was sharp objects (51\%) and this finding was comparable to studies from Kaur et al who had $73.67 \%,{ }^{11}$ but this finding was not supported by Angelino et $\mathrm{al}^{13}$ and Aboel-Fetoh et $\mathrm{al}^{15}$ study. Sports related ocular injury accounted only in $8.7 \%$ of cases in our study however it is reported to be higher in other study. ${ }^{10,12}$ This difference may be due the difference in daily activities of children among various countries worldwide.

Early presentation within 24 hours of ocular trauma was seen among $45.3 \%$ of cases in this study. However, $54.7 \%$ of patients presented late after ocular trauma ranging after 24 hours to 1 month and late presentation may be possibly due to ignorance, illiteracy, poor socioeconomic condition and difficult to access hospital. Among all, 42\% patients underwent surgical intervention. The cases requiring surgical intervention in cases of ocular injury is variable from different parts of the world $17.6 \%-58.3 \%{ }^{13-16}$
Closed globe injury(75\%) was the most frequently observed ocular injury in children in our study, which is consistent with the reports from Angelino et al, ${ }^{13}$ Aboel-Fetoh et al. ${ }^{15}$ Where as open globe injury was the most common cause of ocular injury in studies done Saxena et $\mathrm{Al}^{18}$ Shoja et al, ${ }^{14}$ Hosseini et al. ${ }^{19}$ We found open globe injury to be $25 \%$ among all children with ocular trauma.

Out of 37 open globe injury, corneal perforation (67.56\%) was the commonest ocular manifestation found. This finding is in consistent with reports from Saxena et al $44 \%,{ }^{18}$ Angelino et al $66.7 \% .{ }^{13}$ None of the cases in our study had intraocular foreign body or rupture of globe.

Majority of children (56.7\%) had normal visionin trauma eye at presentation with visual acuity category of 6/6-6/18. Overall we found, $25 \%$ of cases of open globe injury, $75 \%$ of cases of closed globe injury. This finding was consistent with study reported by Saxena et al $^{40}$ and Juan et al, ${ }^{17}$ where higher percentage of cases had no visual impairment in closed globe injury.

We found incidence of post-traumatic endophthalmitis rate at presentation was as $8.1 \%$, which seems to be lesser in compare to other studies $\left(14.0 \%,{ }^{19} 11.91 \%{ }^{10}\right.$ and $\left.54.16 \%{ }^{20}\right)$ this may be due to that other studies had only open globe injuries cases in their study.

\section{CONCLUSION}

As this study was done in a limited time period sample size is small. The irreversible nature of visual loss and immense morbidity associated with it need to be emphasized and publicized. Prevention campaign of ocular trauma is still vital for reducing morbidity and treatment costs associated with pediatric ocular injuries. Parents, elders, teachers and caretakers have an important role to play in prevention of injuries in children. We recommend government and non-government organization to look at the severity of ocular trauma and to take necessary ocular trauma prevention campaign. 


\section{REFRENCES}

1. Rooper Hall MJ. Prevention of blindness from trauma. Trans Ophthalmol 1978; 314-8.

2. Rohrbach JM, Szurman P, Bartz - Schmidt KU. Eye trauma in childhood and youth. Klin Monatsbl Augenheilkd 2004; 221: 631-45.

3. Niiranen M, Raivio I. Eye injuries in children. Br J Ophthalmol 1981; 65 436-438.

4. Grin TR, Nelson LB, Jeffers JB. Eye injuries in childhood. Pediatrics 1987; 80:13-17.

5. LaRoche GR, Mclntyre L, Schertzer RM. Epidemiology of severe eye injuries in childhood. Ophthalmology 1988; 95: 1603-1607.

6. Nelson L, Wilson TW, Jeffers JB. Eye injuries in childhood: demography, etiology and prevention. Pediatrics 1989; 84:438-441.

7. Koirala S et.al, Epidemiology of Ocular injury in pediatric population. National conference on children's sight in Nepal. Organizers: Seva Foundation, Seva Service Society and Nepal Ophthalmic Society, Kathmandu, October 1998.

8. Upadhyay MP, Karmacharya PCD, Koirala S, et al. Epidemiologic characteristics, predisposing factors, and etiologic diagnosis of corneal ulceration in Nepal. Am J Ophthalmol 1991;111:92-9

9. Adhikari RK, Pokhrel H, Chaudhary H, Chaudhary. Ocular trauma among children in western Nepal: agents of trauma and visual outcome. NepJ Oph 2010;2(4):164-165

10. MacEwen, C. J., Baines, P. S. and Desai, P., Eye injuries in children: The current picture. Br. J. Ophthalmol., 1999; 83: 933-936.
11. Apjit Kaur and Ajai Agrawal ; Pediatric ocular trauma. CURRENT SCIENCE 2005; 89(1):43-46.

12. Grin TR, Nelson LB, Jeffers JB. Eye injuries in childhood. Pediatrics 1987; 80: 13-17.

13. Angelino Julio Cariello,Nilva Simerem Bueno Moraes,Somaia Mitne, Celina Shizuka Oita,Bruno Machado Fontes,Luiz Alberto Soares Melo. Epidemiological findings of ocular trauma in childhood Arq Bras Oftalmol. 2007;70(2):271-5

14. M. R. Shoja , A. M. Miratashi. Pediatric ocular trauma Acta Medica Iranica, 2006;44(2): 125-130.

15. Nagah Mohamed Aboel-Fetoh et,al, Pattern of Childhood Ocular Trauma; The Egyptian Journal of Community Medicine April 2009; Vol. 27 No. 2

16. Poon AS, Ng JS, Lam DS, Fan DS, Leung AT. Epidemiology of severe childhood eye injuries that required hospitalization. Hong Kong Med J. 1998;4:371-4.

17. Serrano JC, Chalela P, Arias JD. Epidemiology of childhood ocular trauma in a northeastern Colombian region.Arch Ophthalmol. 2003, 121:1439-1445.

18. Saxena R, Sinha R, Purohit A, Dada T, Vajpayee RB, Azad RV. Pattern of pediatric ocular trauma in India. Indian J Pediatr 2002; 69: 863-7.

19. Hamid Hosseini et.al: Clinical and Epidemiologic Characteristics of Severe Childhood Ocular Injuries in Southern Iran; Middle East Afr J Ophthalmol. 2011 Apr-Jun; 18(2): 136-140

20. Narang S, Gupta V, Simalandhi P, et.al, Paediatric open globe injuries. Visual outcome and risk factors for endophthalmitis, Indian J Ophthalmol. 2004; 52:29-34. 